
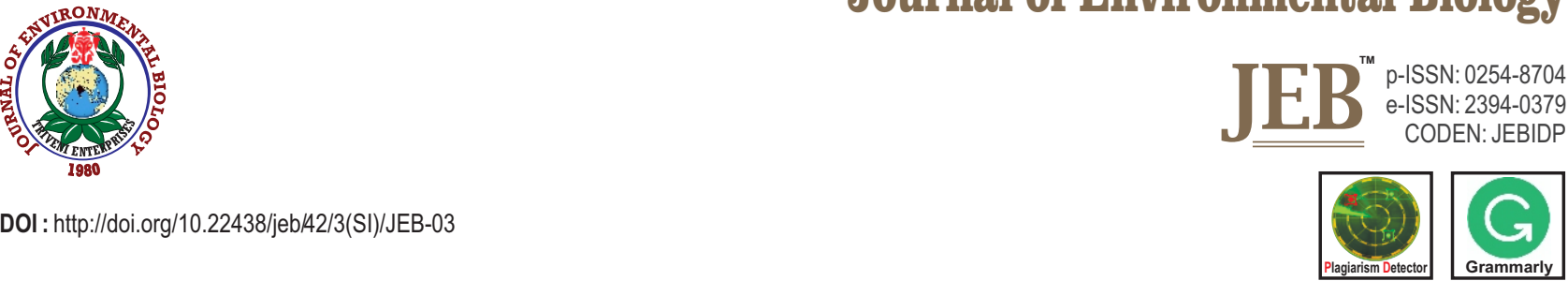

\title{
Boron removal from aqueous solution using coagulation- flocculation with curcumin : A response surface methodology
}

\author{
A.A. Halim ${ }^{1 *}$, M.M. Hanafiah ${ }^{1,2}$, M. Asmi ${ }^{1}$ and Z. Daud ${ }^{3}$ \\ 'Department of Earth Sciences and Environment, Faculty of Science and Technology, Universiti Kebangsaan Malaysia, Bangi, 43600, Malaysia \\ ${ }^{2}$ Centre for Tropical Climate Change System, Institute of Climate Change, Universiti Kebangsaan Malaysia, Bangi, 43600, Malaysia \\ ${ }^{3}$ Faculty of Civil Engineering and Built Environment, Universiti Tun Hussein Onn Malaysia, Parit Raja, 86400, Malaysia \\ *Corresponding Author Email : azharhalim@ukm.edu.my
}

\section{Abstract}

Aim: Application of response surface methodology (RSM) to determine optimum parameters in the coagulation-flocculation process aided by curcumin for boron removal from aqueous solution was investigated.

Methodology: Different parameters such as $\mathrm{pH}$, coagulant dosage, and curcumin dosage that effect boron removal were tested. Application of central composite design in RSM was used to design the coagulation-flocculation experiment.

Results: The results showed $75 \%$ of boron removal, while the optimum parameters for boron removal were observed at $\mathrm{pH} 2.8,132.05$ ppm poly aluminum chloride dose and 1161.4 ppm curcumin dose, respectively.

Interpretation: Quadratic regression showed that the model was significant and lack of fit $P$ value was $0.107(p>0.05)$, implying a significant model correlation between the variables and responses. The experimental data and predicted model proved that RSM is an appropriate approach for optimising the coagulation-flocculation process in removing boron from aqueous solution.

Key words: Boron, Coagulation, Curcumin, Flocculation, Response surface methodology

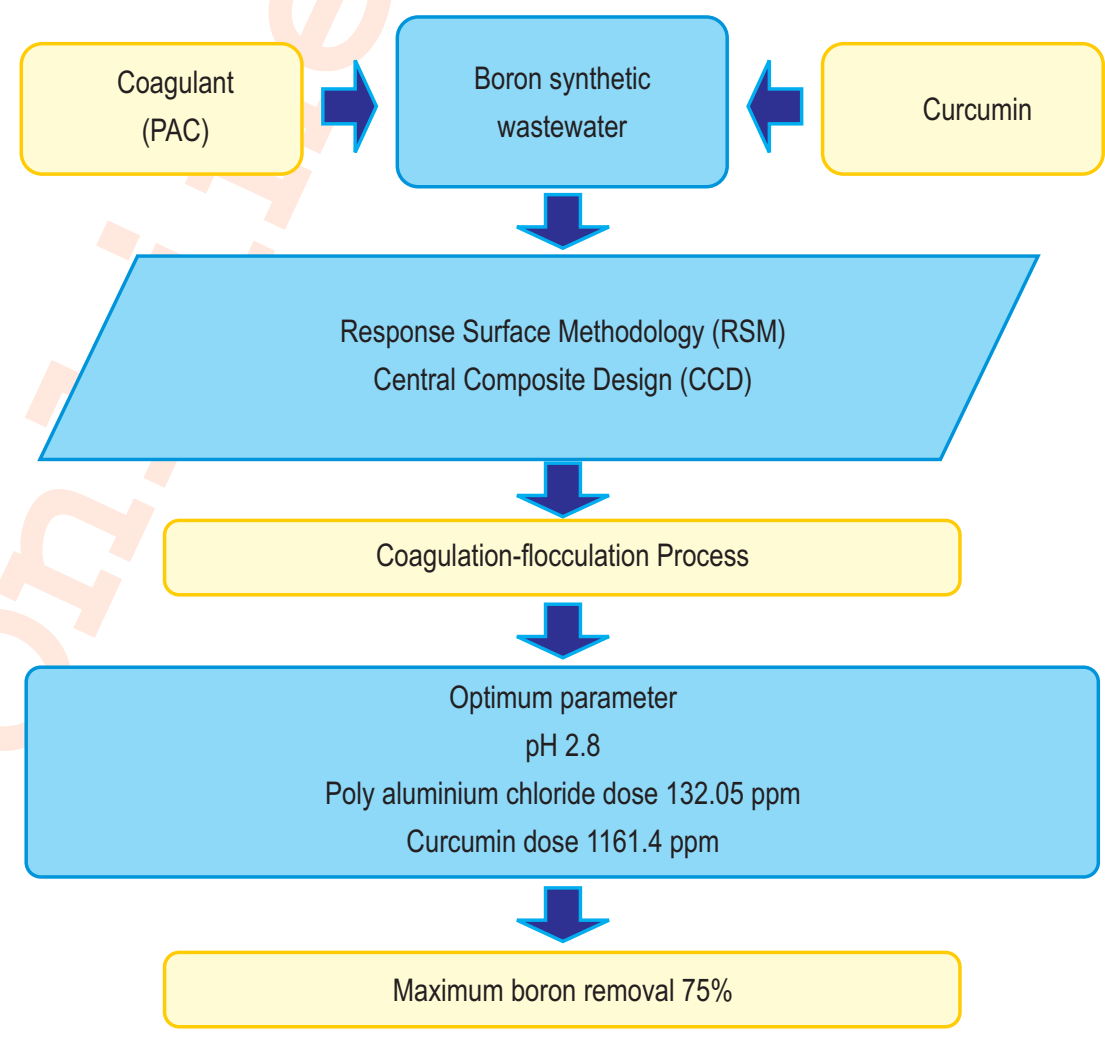

How to cite : Halim, A.A., M.M. Hanafiah, M. Asmi and Z. Daud: Boron removal from aqueous solution using coagulation-flocculation with curcumin :Aresponse surface methodology. J. Environ. Biol., 42, 750-755 (2021). 


\section{Introduction}

The presence of boron can be detected naturally in low concentrations in soil, water and rocks (Yilmaz et al., 2007).. Total boron dose recommended by the World Health Organization is 1$13 \mathrm{mg} \mathrm{day}^{-1}$ is safe and adequate for human health (Simsek et al., 2003). The element of boron is widely used especially in production of glass and detergents (Ozturk and Kavak, 2005; Magara et al., 1998), cosmetics, heat-resistant glasses, ceramics, and fire retardants materials (Demey et al., 2019; Kartikaningsih, 2016) and as a moderator in nuclear reactor (Coughlin, 1998; Silva et al., 2019). The use of inactive sepiolite waste (ISW) and the remaining active sepiolite waste (ASW) as coagulants can help in the removal of boron from aqueous solutions by adsorption processes using batch and column (Ozturk and Kavak, 2004). Electrocoagulation process has also been used for treating wastewater containing boron in an effective and efficient manner (Yilmaz et al., 2008; Halim et al., 2012).

Removal of boron from aqueous solutions can be carried out done through precipitation and coagulation (Yilmaz et al., 2007; Halim et al., 2012), electro-coagulation (Silva et al., 2019), activated carbon adsorption, fly ash and oxides (Cengeloglu et al., 2007; Kurkumin et al., 2013; Hu et al., 2020), ion exchange (Bai et al., 2020; Boncukcuoglu et al., 2004), extraction solvent after complexation (Matsumoto et al., 1997), reverse osmosis (Cengeloglu et al., 2008) and electrodialysis (Yazicigil and Oztekin, 2006). Coagulation and flocculation are considered as one of the effective methods for wastewater treatment. Addition of chemicals in the process of coagulation and flocculation has aided in the removal and modification of physical state of suspended solids and dissolved (Verma et al., 2004). High cost required for wastewater treatment, and biological treatment is said to be less productive for the removal of boron from industrial wastewater (Melnyk et al., 2005).

Curcumin, demethoxycurcumin and bisdemethoxy curcumin are known as curcuminoids. Curcumin (diferuloyl methane) is a polyphenol and active ingredient of Curcuma longa. Curcumin I (curcumin), Curcumin II (demethoxy curcumin) and Curcumin III (bisdemethoxy curcumin) are three main yellow pigments of turmeric (Goel et al., 2008). Curcumin can be used as a coagulant in the wastewater treatment. Halim et al. (2012) found that curcumin-based coagulant was able to remove boron from aqueous solution by $95 \%$ as compared to normal coagulant $62 \%$. Electrocoagulation process aided by curcumin was more efficient in removing boron than the unaided electrocoagulation process (Halim et al., 2012). In view of the above, this study was carried out to determine the optimal process involved in removal of boron from the aqueous solution by curcumin aided coagulationflocculation using response surface methodology.

\section{Materials and Methods}

Poly-aluminum chloride was used as a coagulant in this study. Poly-aluminum chloride and curcumin were purchased from Merck Company. Boron stock solution was prepared from boric acid powder. Optimum parameters like $\mathrm{pH}$, poly-aluminum chloride and curcumin doses were determined based on the effectiveness of boron removal.

Estimation of optimum parameters ( $\mathrm{pH}$, coagulant dosage and curcumin dosage): For $\mathrm{pH}, 400 \mathrm{ml}$ of boron solution with concentration at $50 \mathrm{mg} \mathrm{l}^{-1}$ was filled in each of six beakers to 500 $\mathrm{ml}$. Each beaker was adjusted between $\mathrm{pH} 6$ to 11 . After that, 90 $\mathrm{ml} \mathrm{PAC}$ and $5 \mathrm{ml}$ curcumin were loaded into the beaker. Next, after the jar test was completed, a total of $50 \mathrm{ml}$ of the test sample was taken and stored in bottles for the determination of boron content. For PAC dosage, jar tests were conducted using different doses of PAC in the range of 50-100 ml. Each beaker was then filled with $400 \mathrm{ml}$ of boron and $5 \mathrm{ml}$ of curcumin. After $30 \mathrm{~min}, 50 \mathrm{ml}$ of sample was taken and stored in a bottle for estimation boron by Carmine method (Eaton and Franson, 2005). For curcumin dosage, six beakers containing $400 \mathrm{ml}$ of boron were prepared and filled with different doses of curcumin $(2,4,6,8,10$ and 12 $\mathrm{ml})$. After that, all the beakers were prepared for the test tube for the time chosen. Finally, $50 \mathrm{ml}$ samples were taken and stored for further process.

Optimization by response surface methodology and statistical analysis: Design of the experiments and statistical analysis were conducted using Minitab software (ver. 16). Central composite design (CCD) in the response surface methodology was employed to determine the optimisation parameters. The effects on response were compared after different variables that were expressed in different units and variation limits were coded. Variables $X_{i}$ were coded as $x_{i}$ based on the equation below:

$$
X i=\frac{X_{i}-X_{i, 0}}{\delta X_{i}}
$$

Where, $X_{i}$ refers to the coded value of independent variable $i ; x_{i}$ is the uncoded value of independent variable $l ; x_{i, 0}$ is the median of data array $x_{i}$; and $\delta x_{i}$ is the step change. Step change $\delta x_{i}$ is expressed as below:

$$
\delta x_{i}=\frac{\max \left(x_{i}\right)-\min \left(x_{i}\right)}{2}
$$

$\mathrm{pH}\left(\mathrm{x}_{1}\right)$, dose of coagulant, PAC $\left(\mathrm{x}_{2}\right)$, dose of coagulant aid, curcumin $\left(x_{3}\right)$ were selected as three independent variables. The dependent variable or response was fitted by a second-order model in the form of a quadratic polynomial equation:

$$
Y m=b_{0}+\sum_{i=1}^{k} b_{i} X_{i}+\sum_{i=1}^{k} b_{i i} X_{i}^{2}+\sum_{i}^{i j j} \sum_{j} b_{i j} X_{i} X_{j} \ldots \ldots \ldots
$$


Table 1: Coded and non-coded values of RSM application for curcumin aided coagulation-flocculation process

\begin{tabular}{|c|c|c|c|c|c|c|c|}
\hline \multirow{2}{*}{$\begin{array}{l}\text { Order of } \\
\text { study }\end{array}$} & \multicolumn{3}{|c|}{ Coded value } & \multicolumn{3}{|c|}{ Non-coded value } & \multirow{2}{*}{$\begin{array}{l}\text { Response }(\mathrm{Y}) \text {, } \\
\text { \% boron removal }\end{array}$} \\
\hline & $\mathrm{pH}\left(\mathrm{X}_{1}\right)$ & $\begin{array}{l}\text { Dose of } \\
\operatorname{PAC}\left(X_{2}\right)\end{array}$ & $\begin{array}{l}\text { Dose of curcumin } \\
\left(\mathrm{mgl}^{-1}\right)\left(\mathrm{X}_{3}\right)\end{array}$ & $\mathrm{pH}$ & $\begin{array}{l}\text { Dose of PAC } \\
\left(\mathrm{mgl}^{-1}\right)\end{array}$ & $\begin{array}{l}\text { Dose of curcumin } \\
\left(\mathrm{mgl}^{-1}\right)\end{array}$ & \\
\hline 1 & -1 & 1 & -1 & 4.5 & 65 & 500 & 75 \\
\hline 2 & 0 & 0 & 0 & 7 & 90 & 1000 & 67 \\
\hline 3 & 0 & 0 & -1.68 & 7 & 48 & 159.1 & 25 \\
\hline 4 & 0 & 0 & 1.68 & 7 & 132 & 1840.9 & 58 \\
\hline 5 & 0 & 0 & 0 & 7 & 90 & 1000 & 42 \\
\hline 6 & 1 & -1 & 1 & 9.5 & 115 & 1500 & 42 \\
\hline 7 & 0 & 0 & 0 & 7 & 90 & 1000 & 58 \\
\hline 8 & -1 & -1 & -1 & 4.5 & 65 & 500 & 25 \\
\hline 9 & 0 & 0 & 0 & 7 & 90 & 1000 & 58 \\
\hline 10 & 1.68 & 0 & 0 & 11.2 & 90 & 1000 & 25 \\
\hline 11 & 0 & 0 & 0 & 7 & 90 & 1000 & 50 \\
\hline 12 & 1 & -1 & -1 & 9.5 & 65 & 500 & 50 \\
\hline 13 & -1.68 & 0 & 0 & 2.8 & 90 & 1000 & 75 \\
\hline 14 & 1 & 1 & -1 & 9.5 & 65 & 500 & 33 \\
\hline 15 & 0 & 0 & 0 & 7 & 90 & 1000 & 42 \\
\hline 16 & 0 & 1.68 & 0 & 7 & 90 & 1000 & 42 \\
\hline 17 & 1 & 1 & 1 & 9.5 & 115 & 1500 & 58 \\
\hline 18 & -1 & -1 & 1 & 4.5 & 115 & 1500 & 50 \\
\hline 19 & -1 & 1 & 1 & 4.5 & 115 & 1500 & 58 \\
\hline 20 & 0 & -1.68 & 0 & 7 & 90 & 1000 & 50 \\
\hline
\end{tabular}

Where, $i$ is the linear coefficient, $j$ is the quadratic coefficient; $b$ is the regression coefficient; and $k$ is the number of factors studied and optimised in the experiments. A two-dimensional contour plot was used to illustrate the interactive effects of independent variables on dependent variables. Each parameter was calculated to obtain relevant data to be included in the RSM for the next forecast. Coagulation-flocculation process was carried out using the parameters obtained by RSM based on the noncoded values as shown in Table 1.

\section{Results and Discussion}

Fig. 1(a) shows a surface plot for efficient removal of boron which PAC dose at coded value of 0.75 or at $108.6 \mathrm{ppm}$ and the dose of curcumin was observed at coded value of 0.75 or at concentration of $1375 \mathrm{ppm}$. Based on these plots, the removal of boron was $55 \%$. Fig. 1 (b) shows the surface plot for the removal of boron was effective at a pH coded value of $-1.25(\mathrm{pH} 3.9)$, while the dose of curcumin was at coded value of 0.5 (1250 ppm). Percentage removal of boron at this $\mathrm{pH}$ and curcumin dose was $60 \%$. Fig. 1(c) shows the surface plot for the efficient removal of boron, where the $\mathrm{pH}$ coded value was at $-1.5(\mathrm{pH} 3.3)$, and the coagulant dose coded value was 1.4 (125 ppm). Percentage removal of boron at this $\mathrm{pH}$ and coagulant dose was $80 \%$.

Each $\mathrm{pH}$ level varied to affect the effectiveness of boron removal either in acidic, alkaline or neutral conditions. In Fig. 1(b) shows that at pH 3.9 (acidic condition) the percentage of boron removal was $>60 \%$. High boron content in the aqueous soluble in acidic conditions can remove boron more effectively from the aqueous solution. At acidic $\mathrm{pH}$, the positive charge present in the solution is easily generated. It is reasonable to make the adsorption of borate anion in acidic condition (Polowczyk et al., 2013).

Fig. 1C shows that the removal of boron was $>80 \%$ at $\mathrm{pH}$ 3.3. This removal was higher than the percentage of boron removal between $\mathrm{pH}$ and the dosage of $\mathrm{PAC}$, implying the coagulant material was more effective in the removal of boron in surface charge (Moghaddam et al., 2010). According to Wei et al. (2011), borate ions in solution become more predominant species below $\mathrm{pH} 7$ that leads to a negatively charged surface. Below $\mathrm{pH}$ 7 , boron exists as boric acid. It can exist predominantly as boric acid, $\mathrm{B}(\mathrm{OH})_{3}$, which cannot be separated in the aqueous liquid (Avraham et al., 2011). According to Oo et al. (2009), the total percentage of dissociation of boric acid to borate containing negative charges occurring at an alkaline $\mathrm{pH}$ level. Therefore, boric acid in aqueous solution can be removed in the form of borate.

In Fig. 1 (a), at PAC concentration of 108.8 ppm, the boron removal efficiency was above $55 \%$. High coagulant doses content helps in destabilization of the colloidal particles in solution (Syafalni et al., 2012). Fig. 1(c) shows that the boron removal was above $80 \%$ at PAC concentration of $105 \mathrm{ppm}$ and $\mathrm{pH}$ 3.3. The behavior of coagulation of PAC is associated with the ability of high charge neutralization, adsorption and sweep flocculation 

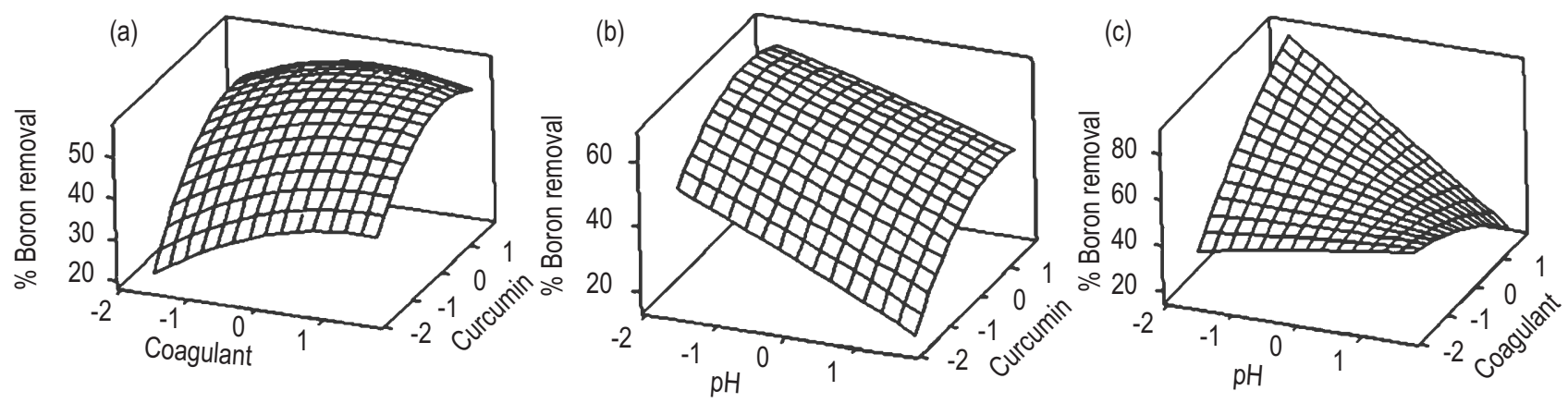

Fig. 1 : Surface plot of boron removal (in percentage) vs (a) coagulant and curcumin, (b) pH and curcumin, (c) pH and coagulant in coded value.

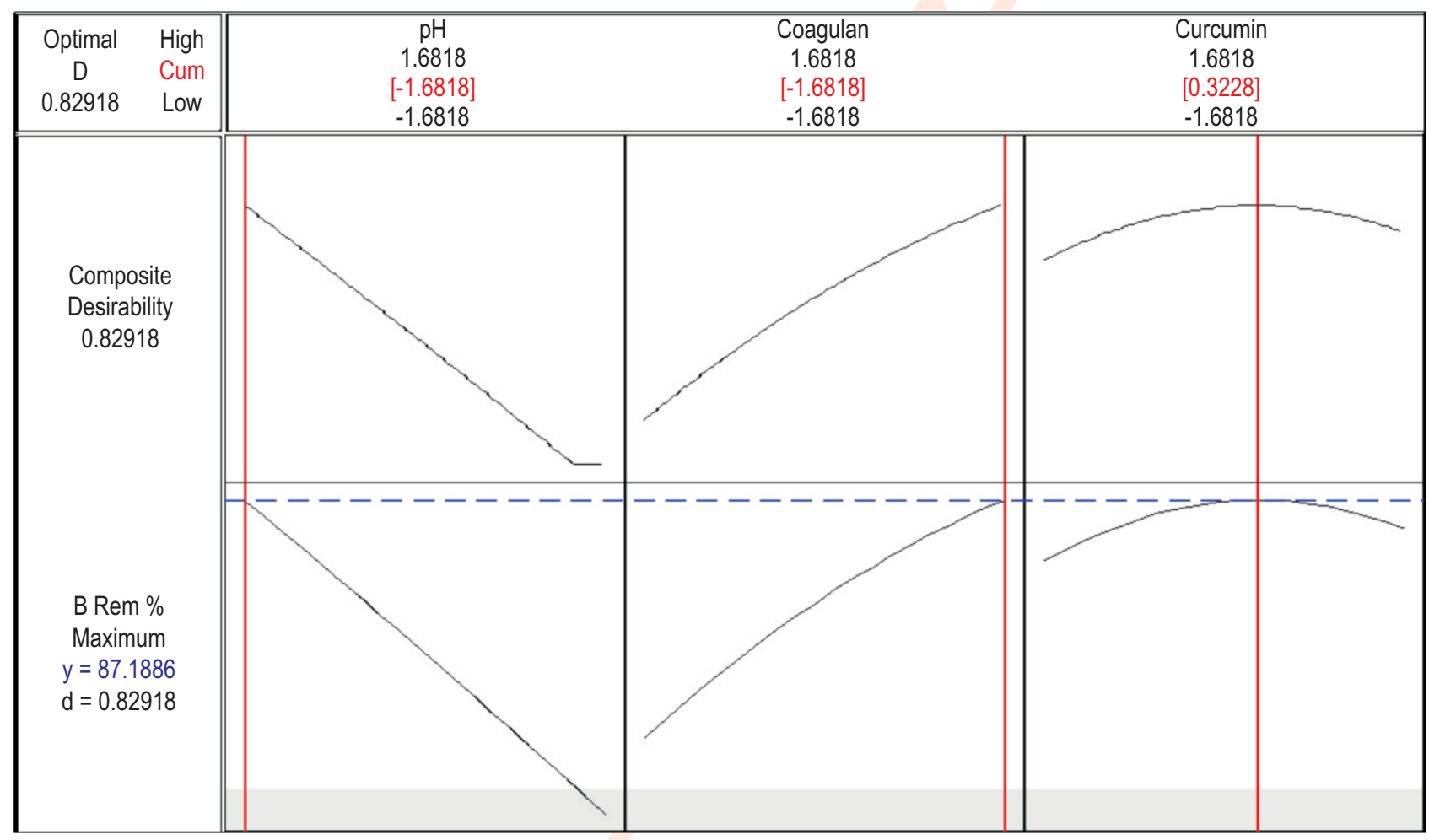

Fig. 2 : Optimization plot of curcumin aided coagulation-flocculation process for boron removal.

(Moghaddam et al., 2010). The high rate of boron removal was due to sweep mechanism for flocculation, which occurs at highdose PAC. Fig. 2 associates the percent removal of boron correlated between $\mathrm{pH}$ and dosage of PAC. According to HanQing et al. (2011), colloidal particles in solution are destabilized by the coagulant, and flocculant consumption in the coagulationflocculation process helps in clotting particles of colloidal size to merge into larger particles.

Dose of curcumin is one of the variables used in the coagulation-flocculation to influence the process of boron removal, which acts as a coagulant aid. As shown in Fig. 1 (a), at curcumin dose of $1375 \mathrm{ppm}$, boron removal was higher than $55 \%$. Total removal of boron is associated with high concentration of coagulant dosage. This indicates that high curcumin dose is not appropriate for producing high boron removal. In Fig. 1 (b), the removal of boron was $>60 \%$ resulting in doses of curcumin at high concentrations of $1,250 \mathrm{ppm}$. Total removal was low due to low $\mathrm{pH}$. In acidic solution, boric acid reacts with curcumin to form rosocyanine (Lee et al., 2011). Rosocyanine is a large molecule that coagulates/ precipitate in the presence of $\mathrm{Al}^{3+}$ ions. This study shows that the boron removal in the coagulation-flocculation process was assisted by the addition of curcumin as a coagulant aid.

Fig. 2 shows the suggested optimum parameters for the most efficient boron removal. Suggested optimum coded 


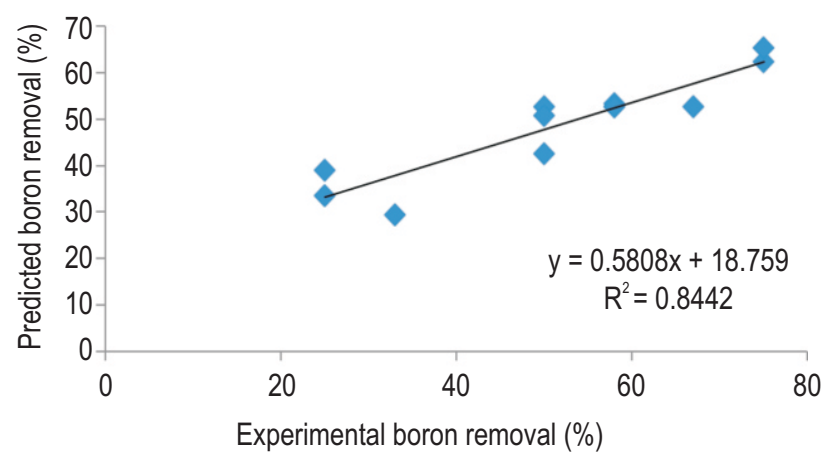

Fig. 3 : Predicted vs. Experimental plot of boron removal by curcumin aided coagulation-flocculation process.

values for $\mathrm{pH}$, coagulant dose and curcumin dose were -1.6818 (pH2.8), 1.6818 (123.05 ppm) and 0.3228 (1161.4 ppm), respectively. For the recommended $\mathrm{pH}$, reading was at low $\mathrm{pH}$, which causes lower boron removal rate due to the acidic $\mathrm{pH}$ conditions. In addition, high concentrations of PAC at 132.05 ppm, helped in increasing the removal of boron. The optimal concentrations of curcumin at 1,161.4 ppm also helped in the effective removal of boron.

In this study, important factors such as $\mathrm{pH}, \mathrm{PAC}$ and curcumin doses affected the percentage of boron removal from aqueous solution. Regression equation model for boron removal in curcumin aided coagulation-flocculation process is given below:

$Y=52.72-7.99 X_{1}+3.19 X_{2}+5.89 X_{3}-0.27 X_{1}^{2}-1.68 X_{2}^{2}-3.27 X_{3}^{2}$ $-7.37 X_{1} X_{2}+1.13 X_{1} X_{3}-1.13 X_{2} X_{3}$

Based on the above equation, the correlation between $\mathrm{X}_{1}(\mathrm{pH}), \mathrm{X}_{2}$, and $\mathrm{X}_{3}$ (coagulant and curcumin dose in $\mathrm{ppm}$ ) towards boron removal, $Y$ was determined. Referring to this equation, the removal of boron (\%) with linear and quadratic relationships with $\mathrm{pH}, \mathrm{PAC}$ and curcumin. Analysis of variance (ANOVA) was used to analyse the interaction between process variables and responses. The lack of fit F-test was used to test whether the regression function adequately fits in the data. The quadratic regression showed that the model was significant, lack of fit $P$ value was $0.107 \quad(P>0.05)$, implying a significant model correlation between the variables and responses. Fig. 3 shows that the predicted boron removal values plot versus experimental boron removal values were distributed close to the straight line. The correlation coefficient value $\left(R^{2}=0.8442\right)$ indicates that only $15.58 \%$ of total variation could not be explained by the empirical model (Ahamad et al., 2005).

A coagulation-flocculation test was carried out to remove boron from aqueous solution, using poly-aluminum chloride as a coagulant, aided with curcumin. A full factorial central composite design and response surface design were used to optimize the coagulant dosage, curcumin dosage and $\mathrm{pH}$ levels. The results showed that optimal conditions for boron removal were at a coagulant dosage of $132.05 \mathrm{ppm}$, curcumin dosage of $1161.4 \mathrm{ppm}$ and pH 2.8, The significant correlation between experimental data and predicted model proved that RSM is a suitable approach for optimizing the coagulationflocculation process in removing boron from aqueous solution.

\section{Acknowledgments}

The authors gratefully acknowledge Universiti Kebangsaan Malaysia for supporting this research (GUP-2019042).

\section{Add-on Information}

Authors' contribution: A.A. Halim: Research idea, experimental design, data analysis, manuscript writing; M.M. Hanafiah: Manuscript writing; M. Asmi: Laboratory work and experimental, data analysis and manuscript writing; $\mathbf{Z}$. Daud: Manuscriptwriting.

Research content: The research content is original and has not been published elsewhere

Ethical approval: NotApplicable

Conflict of interest: The authors declare that there is no conflict of interest.

Data from other sources: NotApplicable

Consent to publish: All authors agree to publish the paper in Journal of Environmental Biology.

\section{References}

Ahamad, A.L., S. Ismail and S. Bhatia: Optimization of coagulationflocculation process for palm oil mill effluent using response surface methodology. Environ. Sci. Technol., 39, 2828-2834 (2005).

Avraham, E., M. Noked, A. Soffer and D. Aurbach: The feasibility of boron removal from water by capacitive deionization. Electrochim. Acta, 56, 6312-6317 (2011).

Bai, S., J. Han, C. Du, J. Li and W. Ding: Removal of boron and silicon by a modified resin and their competitive adsorption mechanisms. Environ. Sci. Pollut. Res., 27, 30275-30284 (2020).

Boncukcuoglu, R., A.E. Yilmaz, M. Muhtar Kocakerim and M. Copur: An empirical model for kinetics of boron removal from boroncontaining wastewaters by ion exchange in a batch reactor. Desalination, 160, 159-166 (2004).

Cengeloglu, Y., G. Arslan, A. Tor, I. Kocak and N. Dursun: Removal of boron from water by using reverse osmosis. Sep. Purif. Technol., 64, 141-146 (2008)

Cengeloglu, Y., A. Tor, G. Arslan, M. Ersoz and S. Gezgin: Removal of boron from aqueous solution by using neutralized red mud. $J$. Hazard. Mater., 142, 412-417 (2007).

Coughlin, J.R.: Sources of human exposure. Bio. Trace Elem. Res., 66, 
87-100 (1998).

Demey, H., J. Barron-Zambrano, T. Mhadhbi, H. Miloudi, Z. Yang, M. Ruiz and A.M. Sastre: Boron removal from aqueous solutions by using a novel alginate-based sorbent: comparison with $\mathrm{Al}_{2} \mathrm{O}_{3}$ particles. Polymers, 11, 1509 (2019).

Eaton, A.D. and M.A.H. Franson: Standard Methods for the Examination of Water and Wastewater. $21^{\text {st }}$ Edn., American Public Health Association, Washington, DC., USA(2005).

Goel, A., A.B. Kunnumakkara and B.B. Aggarwal: Curcumin as "Curcumin": From kitchen to clinic. Biochem. Pharmacol., 75, 787809 (2008).

Hu, G., W. Zhang, Y. Chen, C. Xu, R. Liu and Z. Han: Removal of boron from water by GO/ZIF-67 hybrid material adsorption. Environ. Sci. Pollut. Res., 27, 28396-28407 (2020).

Kartikaningsih, D., Y.J. Shih and Y.H. Huang: Boron removal from boric acid wastewater by electrocoagulation using PACinum as sacrificial anode. Sustain. Environ. Res., 26, 150-155 (2016).

Lee, H., J.H. Lee, S. Kang, J.Y. Lee, G. John and J.H. Jung: Pyridinebased coordination polymeric hydrogel with $\mathrm{Cu}^{2+}$ ion and its encapsulation of a hydrophobic molecule. Chem. Commun., 47, 2937-2939 (2011).

Halim, A.A., A.F.A. Bakar, M.A.K.M. Hanafiah and H. Zakaria: Boron removal from aqueous solutions using curcumin-aided electrocoagulation. Middle East J. Sci. Res., 11, 583-588 (2012).

Halim, A.A., N.H. Thaldiri, N. Awang and M.T. Latif: Removing boron from an aqueous solution using turmeric extract-aided coagulationflocculation. Am. J. Environ. Sci., 8, 322-327 (2012).

Kurkumin, T.T., A.A. Halim, N.A. Roslan, N.S. Yaacub and M.T. Latif: Boron removal from aqueous solution using curcuminimpregnated activated carbon. Sains Malays., 42, 1293-1300 (2013).

Magara, Y., A. Tabata, M. Kohki, M. Kawasaki and M. Hirose: Development of boron reduction system for sea water desalination. Desalination., 118, 25-34 (1998).

Matsumoto, M., K. Kondo, M. Hirata, S. Kokubu, T. Hano and T. Takada: Recovery of boric acid from wastewater by solvent extraction, Sep. Sci. Technol., 32, 983-991 (1997).

Melnyk, L., V. Goncharuk, I. Butnyk and E. Tsapiuk: Boron removal from natural and wastewaters using combined sorption/membrane process, Desalination., 185, 147-157 (2005)
Moghaddam, S.S., M.A. Moghaddam and M. Arami: Coagulation/ flocculation process for dye removal using sludge from water treatment plant: Optimization through response surface methodology. J. Hazard. Mater., 175, 651-657 (2010).

Oo, M.H. and L. Song: Effect of pH and ionic strength on boron removal by ro membranes. Desalination, 246, 605-612 (2009).

Öztürk, N. and D. Kavak: Boron removal from aqueous solutions by adsorption on waste sepiolite and activated waste sepiolite using full factorial design. Adsorption, 10, 245-257 (2004).

Ozturk, N. and D. Kavak: Adsorption of boron from aqueous solutions using fly ash: Batch and column studies. J. Hazard. Mat., 127, 8188 (2005).

Polowczyk, I., J. Ulatowska, T. Koźlecki, A. Bastrzyk and W. Sawiński: Studies on removal of boron from aqueous solution by fly ash agglomerates. Desalination, 310, 93-101 (2013).

Silva, D.M.L.D., M.T.W. Carneiro and J. Ribeiro: Boron removal from mining and synthetic effluents by electrocoagulation using PACinum electrodes. Sci. World J., 2019, 1-7 (2019).

Şimşek, A., D. Korkmaz, Y.S. Velioglu and O.Y. Ataman: Determination of boron in hazelnut (Corylus avellana L.) varieties by inductively coupled plasma optical emission spectrometry and spectrophotometry. Food Chemistry, 83, 293-296 (2003).

Syafalni, S., H.K. Lim, N. Ismail, I. Abustan, M.F. Murshed and A. Ahmad: Treatment of landfill leachate by using lateritic soil as a natural coagulant. J. Environ. Manage., 112, 353-359 (2012).

Verma, C.B., B. Lallu and R.S. Yadav: Effect of B and Zn application on growth and yield of pigeonpea. Indian J. Pulses Res., 17, 149-151 (2004).

Wei, Y.T., Y.M. Zheng and J.P. Chen: Design and fabrication of an innovative and environmental friendly adsorbent for boron removal. WaterRes., 45, 2297-2305 (2011).

Yazicigil, Z. and Y. Oztekin: Boron removal by electrodialysis with anionexchange membranes. Desalination, 190, 71-78 (2006).

Yilmaz, A.E., R. Boncukcuoğlu, M.M. Kocakerim, M.T. Yilmaz and C. Paluluoğlu: Boron removal from geothermal waters by electrocoagulation. J. Hazard. Mater., 153, 146-151 (2008).

Yilmaz, A.E., R. Boncukcuoğlu and M.M. Kocakerim: An empirical model for parameters affecting energy consumption in boron removal from boron-containing wastewaters by electrocoagulation. J. Hazard. Mater., 144, 101-107 (2007). 